\title{
REPENSAR LA CIUDAD: LA DIMENSIÓN ONTOLÓGICA DE LO URBANO
}

\author{
Daniel Hiernaux
}

Resumen: Los cambios recientes en las ciudades generan numerosas interpretaciones muy diferentes entre sí. Pocos autores, sin embargo, enfrentan una pregunta fundamental: ¿estamos todavía frente a lo que tradicionalmente se ha llamado "ciudad"? Este articulo se orienta a interrogar la dimensión ontológica de la ciudad. Para ello remite a tres dimensiones: lo laberíntico, lo fortuito y lo fugaz, cuya articulación integra la esencia de lo urbano. No todo lo urbanizado actual responde a este modelo, y es a planteamientos como el de Louis Wirth sobre el modo de vida urbano que convendría remitir, entre otros, para replantear las políticas urbanas.

Palabras clave: ontología, ciudad, laberinto, fortuito, fugar:

Daniel Hiernaux, doctor en Geografia por la Universidad de la Sorbona NuevaParis III; profesor investigador titular de la Universidad Autónoma Metropolitana Unidad Iztapalapa de la ciudad de México, en la licenciatura en geografia humana. Miembro del Sistema Nacional de Investigadores, nivel 3. Temas principales de investigación: geografía urbana; geografía del turismo y del tiempo libre; epistemología de la geografia. Departamento de Sociología. Edificio H. División de Ciencias Sociales y Humanidades, San Rafael Atlixco, 186, colonia Vicentina, Delegación Iztapalapa, C. P. 09430, México, D. F., tel: UAM 5804 6466, fax: 5612 5682, correo electrónico: danielhiernaux@gmail.com.
Abstract: The recent changes in cities generate new and different interpretations. Few authors, however, are facing the fundamental question: Are we still facing what traditionally was called a "city"? This paper focuses on the ontological dimension of the city. Therefore, it refers to three dimensions: the labyrinth, the fortuitous, the fleeting, whose articulation integrates the essence of the urban. Not all the actually urbanized space responds to this model; therefore we need to refer to proposals like Louis Wirth' urban way of life, for example to reformulate urban policies.

Key words: ontology, city, labyrinth, fortuitous, fleeting.

\section{Introducción}

$\mathrm{H}$ oy, cuando las ciudades cambian tan velozmente como las sociedades, surge la impresión de que todo el conocimiento que la humanidad ha acumulado sobre la historia de las mismas está erosionándose por la intensidad y, casi, por la violencia misma del proceso de cambio.

Los ejemplos surgen profusamente: desde las redes que cruzan de forma invisible los espacios urbanos para distribuir información 0 , a veces, mentiras o nuevas leyendas urbanas - como la noticia de la existencia de una banda denominada "sangre" en la ciudad de México a fines de 2005-, hasta la proliferación de 
conjuntos amurallados donde encierran sus miedos quienes tienen lo que los demás anhelan. Son muchas las facetas de estas "nuevas ciudades" que se presentan a nuestros ojos. Más aún, resulta sobrecogedor observar que las mismas tendencias, los mismos miedos, las mismas ilusiones de modernidad, avasallan a todos los territorios del mundo.

Dos preguntas, sin embargo, se imponen a quienes pretenden superar la profusión de los elementos visibles para interrogar la esencia misma del fenómeno actual: ¿Cómo interpretar estos cambios?, ¿cómo reconstruir la urdimbre de una tela de la cual sólo vemos los hilos exteriores y el acabado que se nos deja ver?

Después del derrumbe de los grandes discursos, las lecturas de la ciudad actual propuestas por los analistas son muy diferentes y responden a corrientes de pensamiento aún mal establecidas o poco consolidadas. Desde las propuestas postmarxistas de David Harvey (2003) o Neil Smith (1996), pasando por la sociologización del discurso de la globalización que sugiere la obra de Saskia Sassen (1991), hasta las versiones más centradas en la cultura que proponen Néstor García Canclini (2004) o Armando Silva (1992), estamos frente a una ineludible multiplicidad de voces que pretenden descifrar la ciudad contemporánea. Todas, a su manera y en el marco de las limitaciones pero también de las potencialidades que traen consigo sus enfoques, aportan algo al estudio de la ciudad actual.

Igualmente todas remiten a una porción de la realidad, a aquellas dimensiones que se antojan esenciales para entender la ciudad de hoy, sean las migraciones internacionales, los imaginarios urbanos, el peso de las corporaciones internacionales o el modo de gobernanza, por mencionar sólo algunas. Dimensiones, todas ellas, que se derivan del énfasis que los intelectuales presienten necesario otorgar ahora a algún elemento en especial cuando ya se difuminaron las frases hechas, las explicaciones formalizadas que hicieron más fácil, aunque menos creativo, el trabajo de las ciencias sociales de hace algunos lustros. Nos referimos, obviamente, a aquellas explicaciones que partían de propuestas generales, que se aplicaron a contextos diversos con resultados no siempre positivos. Aunque no es nuestro propósito desarrollar esta idea en el contexto de este trabajo, vale subrayar que la investigación sobre la ciudad ha sido particularmente marcada por este tipo de lecturas preestablecidas, donde lo esencial era cubrir los requisitos de una agenda con frecuencia más ideológica que verdaderamente científica.

Por el contrario, la diversidad y riqueza de los enfoques actuales hacen patente que las explicaciones pueden ser múltiples, frente a una realidad fragmentada, retacería de un rompecabezas siempre inconcluso, siempre renovado, parecido al tejido de Penélope. Por ello también, los lectores de estos análisis pueden pasar, ávidamente, de una lectura a otra, de una interpretación aparentemente sin falla a otra que, en cuestión de minutos, se vuelve inconfundiblemente la más atinada, hasta que la sofisticación de una nueva propuesta borra las anteriores, como una marea.

La riqueza de este proceso caótico no debe pasar inadvertida: en vez de discursos contundentes que explican "todo" a partir de algunas aseveraciones decisivas, la multiplicidad de ensayos interpretativos induce la emergencia de diversos hitos, como puntas de iceberg en medio del mar de nuestra incapacidad para entender la ciudad contemporánea. El valor de lo caótico, de lo múltiple, de la diversidad misma, aun en las explicaciones intelectuales, es, sin lugar a dudas, una gran virtud de nuestros tiempos.

Pocos autores, sin embargo, enfrentan una pregunta fundamental, aquélla que debería preceder a todas las demás sobre temas concretos: ¿estamos todavía frente a lo que tradicionalmente se ha llamado "ciudad"? En efecto, seguimos usando la voz "ciudad" para calificar estas urbanizaciones extensas, esta "ciudad difusa", estas formas innovadoras de ocupación del espacio que 
Daniel Hiernaux

impactan nuestro intelecto y nuestros sentidos, como si nada hubiera cambiado desde la "polis" griega, desde el nacimiento del burgo feudal en el medioevo europeo o desde la ciudad industrial decimonónica. En otros términos, la voz que describe las formas de ocupación del espacio parecería haberse congelado mientras que, realidad mediante, nadie podrá negar la profunda transformación de la "ciudad" misma.

No es que no florecieran las propuestas de denominación en una suerte de esfuerzo desesperado por asir un proceso a través de darle un nombre: citábamos, hace un momento, la denominación de "ciudad difusa", una "apelación controlada" recientemente puesta en el mercado, aunque la historia del pensamiento urbano nos permite acumular muchas denominaciones más, desde la "Groszstade" simmeliana (Simmel, 1986), pasando por la "megalópolis" gottmaniana (Gottman y Harper, 1990), hasta llegar a los ensayos contemporáneos, donde leemos sobre la "metápolis" (Ascher, 1995), la "edge city" (Garreau, 1991) y otras "exópolis" (Soja, 2000).

A pesar de este florecimiento ciertamente ilustrativo de denominaciones, quedamos poco satisfechos con lo que se ha aportado para definir la ciudad misma, para ir a la esencia misma de un fenómeno que, a pesar de su larga tradición histórica, quizás esté en vía de desaparición para dar lugar a otras formas de ocupación del espacio. ¿Alguien ha confirmado que el modelo "ciudad" tenía que ser eterno?

Estos temas integran la cuestión fundamental que trataremos en las páginas que siguen. En cierto sentido, ésta es una reflexión ontológica sobre la ciudad, sobre la esencia misma de lo que se ha considerado, desde el renacimiento del proceso urbano en la Europa medieval, como una "ciudad".

Las aportaciones sobre el tema provienen esencialmente de autores que han hecho de la ciudad el tema de una metarreflexión más cercana a la filosofía que a los estudios urbanos tradicionales.
I

Definir la ciudad, indagar en la esencia ontológica de la misma, nos obliga a partir, en primera instancia, de una reflexión sobre su definición tradicional. Para la mayor parte de los autores que la han estudiado y pretendieron definirla, ésta se caracteriza por la concentración de una cierta cantidad de población, una cierta densidad física, la presencia de actividades no directamente ligadas a la producción del campo y un modo de vida distinto del que prevalece en las zonas que — en forma de antinomia — se calificaron como "rurales". Lo anterior ya fue ampliamente estudiado y criticado por Louis Wirth desde 1938 (Wirth, 1988 [1938]).

Este tipo de definición, o más bien el conjunto de definiciones emparentadas que suelen usarse en las ciencias sociales, remite a cuatro campos disciplinarios: la demografía, el urbanismo, la economía y la cultura. Muchos aspectos, sin embargo, fueron apartados por este tipo de enfoque para poder llegar a una definición relativamente sencilla, accesible a todos y, sobre todo, que permite hacer mediciones que pueden ser comparadas internacionalmente.

Lo que se apartó no es para nada secundario: quedaron fuera temas como la organización social — que remite a la sociología-, de igual manera aspectos subjetivos como la formación de los imaginarios que, si bien entra en la dimensión cultural, no aparece con frecuencia en las definiciones de la ciudad. Los temas y campos del conocimiento olvidados u omitidos en esta definición son, ciertamente, tan importantes como los aprovechados. No faltaron autores que, de una manera u otra, remitieron a éstos y otros eslabones perdidos del análisis de la esencia de la ciudad, como la política (en Weber, 1964; Kropotkine, 2003 o Pirenne, 1975, por ejemplo) o la relación con el ambiente/entorno (Bairoch, 1990), pero claramente no son las aportaciones consideradas como las más significativas, y menos aún son las de uso común. 
Lo que definitivamente sobresale de todo ello es la ausencia de una dimensión subjetiva en las definiciones tradicionales de la ciudad: se centran en lo material o en lo visible, en lo supuestamente objetivo, sometido a los criterios de la razón positiva. Así es entonces posible definir la ciudad a partir de su tamaño, criterio bien conocido por los organismos que trabajan lo demográfico, o a partir de lo económico, por ejemplo. Posiblemente, el ejemplo más completo y sofisticado que tenemos de ello en México es la destacada obra de Luis Unikel, El desarrollo urbano de México (1976).

¿Es suficiente? No lo consideramos así. La complejidad de las ciudades supera el marco estrecho de sus dimensiones demográficas, morfológicas o económicas. Más aún, las fronteras entre lo urbano y lo rural se antojan cada vez más endebles a la luz de la creciente "urbanización del campo" que, singularmente, borra de manera progresiva los límites entre modos de vida urbanos y rurales, por lo menos según los criterios tradicionales de delimitación entre ambos campos.

La pregunta sería, entonces: ¿qué es lo que hace que una ciudad sea una ciudad? O, en otros términos, ¿cuál es la esencia misma del hecho urbano?

A esta pregunta nos abocaremos a continuación.

\section{II}

Propondremos una definición de lo urbano que tomará en cuenta tres categorías fundamentales: lo laberíntico, lo fugaz y lo fortuito. Éstas son tres figuras metafóricas a partir de las cuales se puede desvelar la esencia de la ciudad. Son metafóricas porque representan más un estado "absoluto", inalcanzable en forma total, que una realidad concreta. Lo laberíntico no remite a la obligación de que la ciudad se trace como un perfecto laberinto, como el que se encuentra inscrito en el piso de la catedral de Chartres. Tampoco lo fugaz implica que todo se desvanezca al instante, sino que una característica esencial de lo urbano es la ausencia de duración, la volatilidad de las cosas, las personas, las acciones y los pensamientos. Finalmente, lo fortuito no implica la ausencia de organización ni de instituciones, cuando sabemos que, desde la Edad Media, las instituciones fueron decisivas para impulsar el nuevo auge urbano (Pirenne, 1975; Weber, 1964); más bien remite al carácter caótico, espontáneo, de no pocos eventos urbanos.

Pasemos, entonces, a tratar de discernir cada una de las categorías ontológicas que acabamos de mencionar, y a explicar por qué son esenciales para la definición de lo urbano.

\section{La figura del laberinto}

El laberinto es una de las formas más enigmáticas que haya ofrecido la iconografía humana. Desde épocas muy tempranas fue representado por las sociedades humanas y considerado como una figura esencial que ha sido representada en las artes y edificada en arquitectura. Es una forma atractiva y compleja a pesar de cierta obviedad: la obligación de encontrar un recorrido en un entrelazado de vías cerradas.

Michel Foucault expresa acerca del laberinto que no es el lugar donde uno se pierde, sino del cual se sale siempre perdido (Foucault, citado por Attali, 1996: 209). Entrar a un laberinto corresponde metafóricamente a emprender un viaje mental no evidente, construido por avances y retrocesos, que implica también un proceso de memorización para encontrar el camino de salida.

El hombre moderno, el homo urbanus, el que vive en la ciudad, es quien, percibiendo la complejidad del mundo actual, no trata de solucionar su vida cotidiana a partir de trazados rectos y decisiones irrevocables, sino que asume un recorrido laberíntico a través del mundo de la ciudad. Este andar no determinado tampoco refleja una incapacidad para encontrar el camino recto, sino una capacidad adaptativa casi genética que hace que el hombre moderno sea justamente un hombre sabio. La sabiduría, no encontrándose en el respeto de las 
tradiciones, de las normas y pautas establecidas desde tiempos inmemoriales, sino en la capacidad de adaptarse, de encontrar un camino diferente cada vez que se presenta una nueva situación - una esquina del laberinto, donde se tiene que definir el camino a seguir-, es, en esencia, la sabiduría del nómada (Attali, 2003).

La ciudad es claramente una figura metafórica del laberinto o, también, pensándolo como espejo, el laberinto es la metáfora de la ciudad. Aun si proliferaron las ciudades de trazado regular y sencillo de interpretar, no es a su forma material a lo que nos referimos, sino al sentido mismo del abordaje de la ciudad. La ciudad es, antes que todo, una forma socio-espacial cuya interpretación, tanto por el habitante como por el analista, requiere de un andar laberíntico: la complejidad anida en la ciudad y la transforma en un tejido de caminos mentales y físicos que obliga a vaivenes, retrocesos, avances, y raras veces integra la llegada a una salida evidente.

Regresando a la aparente transparencia para el habitante de la ciudad ortogonal, es posible y realista pensar que el camino recto no es siempre la mejor vía. Como lo subraya Jacques Attali: "Aun las ciudades más artificiales nunca pudieron deshacerse del laberinto: la vida no está hecha de líneas rectas" (Attali, 1996: 135). El miedo a lugares poco transitados, la afectividad ligada a ciertos espacios frente a los cuales nos agrada pasar, así como muchos comportamientos modelados por nuestro inconsciente o por nuestros deseos, actúan como una suerte de fuerza mental para desviarnos del camino recto. Nos obligan a seguir, inconscientemente, los dictados del laberinto. Como lo subraya Michel Roux, "el imaginario está en el corazón de las 'realidades' geográficas" (1999: 32).

La ciudad de origen europeo es laberíntica en su trazado. El discurso de la racionalidad propuesto por Hippodamo de Mileto, en su intención de imponer el trazado ortogonal en los asentamientos del hombre, ha sido poco escuchado en la vida cotidiana de las sociedades tradicionales (Paden, 2001).
En los albores de la ciudad moderna, en la urmodernidad como la calificara Walter Benjamin, la figura del laberinto se vuelve a imponer con fuerza a través de la construcción de los pasajes cubiertos de París, y en otras muchas ciudades del mundo, donde esta forma arquitectónica urbana se repetirá de manera más o menos similar. Benjamin retoma la figura dellaberinto en su amplio trabajo sobre los pasajes parisinos. Lo hace a través del montaje literario, que implica numerosas bifurcaciones mentales, algunas inclusive poco evidentes para el lector. Finalmente, para Benjamin la ciudad también es un laberinto, como lo señala Frisby: “... Benjamin concebía ya la ciudad de París como un laberinto y el pasaje como un laberinto que contenía el 'paisaje primitivo del consumo"' (1992: 346). Así, se evidencia que el laberinto, figura antigua, fue retomado, en sus formas básicas, por la modernidad.

Por el contrario, la ciudad moderna de cuño anglosajón parece haber asumido el trazado en forma de damero, de tal suerte que el carácter laberíntico de la ciudad se ha difuminado. Como lo nota Jackson (1994), la manera euclidiana de situarse en el espacio ha sido ampliamente aceptada por la sociedad estadounidense, la cual ha asumido la idea de que la ciudad debe ser transparente, evitando los resquicios, rincones, espacios neutros, impassesy otras formas de organización espacial que se encuentran extensamente en las ciudades tradicionales europeas: la metáfora del laberinto se ha perdido frente a la racionalidad irreprochable del capitalismo protestante, y sabemos a qué grado este modelo urbano se ha expandido a lo largo del mundo. ${ }^{2}$

Sin embargo, la evolución moderna de las ciudades europeas ha incluido en su momento la idea del trazado ortogonal. Podemos citar el caso de las propuestas modernistas de extensión urbana en torno a espacios feudales laberínticos como los "ensanches" - penos particularmente en la propuesta de Cerda para Barcelona—. También, es evidente que la evolución actual de las principales ciudades europeas tiende a una suburbanización que suele darse en damero. 
Si bien la forma no es una dimensión esencial de la ciudad, ni el laberinto es exclusivamente espacial, es evidente que la morfología de las ciudades afecta nuestro modo de vida y, en el caso de las ciudades de traza ortogonal, nos aleja de una concepción laberíntica de la ciudad y, quizás a manera de hipótesis, de la vida misma.

\section{La tiranía de lo fugaz}

El tiempo de las sociedades rurales tradicionales difiere sensiblemente de las temporalidades del mundo urbano. La ciudad implica movimiento, pero quizás, y sobre todo, velocidad. Los ritmos lentos de transformación de las sociedades tradicionales remitían a una vida tranquila, al peso de la tradición, a la omnipresencia de la memoria y de la continuidad que imponían las mismas formas y los mismos espacios de vida, de generación en generación. En otros términos, las posibilidades de cambio eran pocas y, si se manifestaban, ocurrían en el largo plazo.

Por el contrario, la ciudad implicó rápidamente la imposición de un ritmo muy diferente, marcado por la velocidad de las acciones y la escasa trascendencia temporal de los eventos. ${ }^{3}$ Es en ese sentido que lo fugaz se vuelve tiránico: no permite la lentitud, rechaza la permanencia, por lo que la ciudad maldice a quienes no son capaces de seguir las pautas de la fugacidad: ancianos, marginados, niños...

Ciertamente, la construcción de la ciudad denotaba siempre la permanencia, como en el caso de la lenta construcción de las catedrales, pero aun así, los críticos de la arquitectura han evidenciado cómo se transformaba el estilo constructivo a lo largo del proceso de edificación, permitiendo que la transformación pueda y deba leerse en la misma piedra.

La vida urbana, por su parte, estuvo marcada, desde sus principios, por otra temporalidad, cuya racionalidad se puede entender por el paso de la comunidad a la asociación, en el sentido que desarrollaron Tönnies (1979) y Simmel (1986), entre otros. Mientras que la presencia de la comunidad implicó que las relaciones sociales siempre estuvieran marcadas por la omnipresencia del pasado en el presente - reflejado en costumbres, normas y rituales precisos-, la asociación se alcanza sobre la base de un acuerdo entre partes que no tiene más objeto que cumplir con un fin determinado: no existe por tanto una tradición tan fuerte, las costumbres pueden modificarse, por ejemplo, en la medida en que la asociación se logra mejor bajo nuevos parámetros.

Uno de los parámetros esenciales de la asociación es la abstracción de la riqueza que, de ser contabilizada en bienes materiales, se transforma en la inmaterialidad del mismo dinero. Este soporte de las transacciones, el dinero, también transformador potente de las relaciones sociales, se generaliza en las ciudades que inventaron el cheque y posteriormente las formas magnéticas de dinero, permitiendo así la fugacidad de los intercambios, su volatilidad gracias a un soporte inodoro y aparentemente intranscendente de las transacciones.

Georg Simmel observó de forma magnífica esta transformación de las relaciones en el entorno urbano, mostrando que la vida urbana implica el encuentro fugaz entre las personas, sin que ello lleve a la creación de obligaciones mutuas. En la ciudad se prefieren la velocidad y el cambio antes que la duración y la permanencia, lo cual se comprueba en la inestabilidad de la residencia, el cambio laboral, la selección de las actividades lúdicas, así como en la inestabilidad de la familia. La exacerbación de la tendencia a lo fugaz ha sido ampliamente demostrada por los sociólogos urbanos, que evidencian cómo se ha reducido la fidelidad a una residencia, a un lugar de compras, a unas relaciones sociales, en breve, cómo se han creado géneros de vida cada vez más efímeros: es lo que Bauman califica como "modernidad líquida" (2003).

En otro lugar hemos tratado de evidenciar que también existe una nueva geografía de lo fugaz, ya que 
esta cualidad no sólo se refiere a los encuentros o a los intercambios, sino que atañe asimismo a los espacios (Hiernaux, 2006, en prensa). Lo fugaz no es sólo una imposición tecnológica como, por ejemplo, el uso de aparatos de telecomunicación. Se ha vuelto una forma de vivir, una capacidad nueva de ejercer acciones en el tiempo. De hecho, también es una demanda social creciente (Hiernaux, 2005).

Lo fugaz no sólo es demandado, sino que se constituye, en forma quizás contradictoria con lo que se solía ver por el pasado, en una oferta concreta de las instituciones: desfiles — las llamadas "parades", en inglés y francés- oficiales y corporativos, movimientos fugaces propuestos por grupos organizados, eventos instantáneos organizados por la internet entre personas que no se conocen..., todo ello refleja una penetración creciente de lo fugaz en la vida urbana, sin que pareciera ofrecerse mucha resistencia al respecto.

Lo fugaz se vuelve así una característica dominante de la vida urbana, y ello se expresa en todas las esferas de la cotidianidad: públicas y privadas.

\section{La riqueza de lo fortuito}

A la fugacidad se asocia, en forma evidente, el carácter cada vez más fortuito de la vida urbana, también resultado de la evolución propia de las ciudades. Si el laberinto es la representación metafórica de la ciudad, entonces no se puede dudar de que no se sabe lo que aparecerá a la vuelta de la esquina. La ciudad ofrece de esta manera nuevas posibilidades a cada cruce de calles, sea en el sentido tradicional, de una variedad de oferta (Remy, 1966), ${ }^{4}$ sea desde la perspectiva del desarrollo personal del individuo. Que el aire de la ciudad hace libre, como decía Robert Park: "Stadtluft mach free", parece una evidencia, pero que, además, la libertad surgiera a partir de la variedad de posibilidades que ofrece lo fortuito, es la observación complementaria que consolida lo propuesto por ese sociólogo. Jacques
Lévy observa también que "la ciudad ofrece, justamente por la densidad de su diversidad, la posibilidad de lo que se llama en inglés 'serendipity ${ }^{5}$ —una palabra que me gusta mucho: quiere decir que se encuentra lo que no se buscaba" (Lévy, 2003: 83).

Lo fortuito no implica que la ciudad funcione caóticamente, en cuyo caso todo podría ocurrir, sino que la concentración de individuos con experiencias y trayectorias distintas implica que del encuentro de tantas diferencias siempre puede surgir algo nuevo, inesperado, fortuito. En este sentido, la ciudad es cuna de innovaciones porque reúne una multiplicidad de experiencias humanas que, situadas en un sustrato laberíntico, marcado además por la fugacidad de lo que allí ocurre, permite una suerte de combinatoria al infinito de eventos.

Entonces, lo fortuito es una dimensión incontrolable de lo urbano, fuente de innovaciones y de una reconstrucción constante. Esto le permite al escritor Joseph Roth señalar que resulta imposible describir una ciudad de manera definitiva, como parecería que quieren hacerlo las guías turísticas o ciertos relatos de viaje: "Los libros de viaje están dictados por un espíritu estúpido, incapaz de creer en la variabilidad del mundo. [...] El 'buen observador' es el informador más triste. Registra todo cuanto esté sujeto a cambios con los ojos bien abiertos pero rígidos" (Roth, 2000: 9). A pesar de ello, el uso de las guías turísticas sigue vigente; quizás haya que explicarlo por el hecho de que la fugacidad misma de los viajes obliga al manejo de referencias rápidas — “dónde comer", "qué visitar"...- para evitar la confusión ligada también a la profusión.

No ha lugar a dudas que lo fortuito representa una riqueza inagotable de las ciudades. Es una de las principales fuentes por las que siguen resultando atractivas para muchos, aun si otras facetas de las mismas difícilmente son soportables. Lo fortuito aporta una calidad extraordinaria a la vida urbana, la transforma 
en un siempre reempezar, a pesar de los innegables elementos rutinarios que comporta la vida cotidiana.

Así, lo fortuito es lo que permite las pequeñas trasgresiones, las mínimas subversiones que aligeran el peso de la rutina, de la repetición de lo ya conocido: el carácter fortuito de los eventos en la ciudad es la pimienta de la dolorosa experiencia de la rutina.

Sobre lo fortuito se construye la innovación social, la capacidad de las ciudades de constituirse en territorios de lo moderno. Como señalara Charles Baudelaire, la modernidad se basa en lo fortuito. Podríamos agregar que la ciudad sin lo fortuito sería un receptáculo vacío de nuestras vivencias, un simple contenedor de hechos y objetos, un soporte material de la vida, lo que - obvio es - sería invivible para quienes han elegido la vida urbana. Lo anterior no significa que no existan modos de vida alternativos que no recurren o quizás rehúyen de lo laberíntico, lo fortuito y lo fugaz. El "regreso al campo" observable tanto en la proliferación de las segundas residencias como en la migración por largas temporadas de personas hacia ciertos pueblos o regiones tradicionales, es el reflejo de elecciones fundamentales sobre el modo de vida. ${ }^{6}$ En este sentido, Ascher (1995) había advertido ya que, frente a la vida en los nodos urbanos de las "redes metapolitanas", bien se puede elegir vivir en los espacios no articulados.

\section{III}

Las tres características esenciales que hemos presentado en las páginas previas —el carácter laberíntico, la fugacidad y la esencia fortuita de lo urbano_- pueden ser vistas como las tres dimensiones centrales a partir de las cuales podemos construir la ontología de la ciudad.

Estamos lejos, pues, de las definiciones tradicionales de la ciudad: la cantidad de población, su densidad física o la presencia de actividades no rurales; ya no parecen ser suficientes para que un espacio sea urbano.
Todo ello no significa más que intentos técnicos, cuando no tecnocráticos, que reducen la esencia de lo urbano a algunas características esencialmente físicas o económicas. Con base en los criterios anteriores, podemos asumir que el estudio de la ciudad no puede solamente pasar por definir rangos de ciudades por su tamaño, por estudiar variaciones de densidad del centro a la periferia, o por constatar las nuevas profesiones que surgen de la actual "globalización”, entre otros análisis posibles.

Pero quizás debamos empezar una reflexión que podría ser mucho más significativa, la de redefinir la ciudad en otro sentido, particularmente a partir de estas figuras metafóricas que conforman la estructura, los pilares de la construcción del concepto mismo de ciudad.

Hablar de la ciudad difusa, como hace por ejemplo Giuseppe Dematteis (1998), o de exópolis (Garreau, 1991), o de metápolis (Ascher, 1995), entre otras voces, unas más logradas que otras, no resuelve el problema, más bien lo agrava porque estas expresiones parten de la idea de que toda aglomeración humana con ciertas características oficiales sigue siendo, en cierta forma, una ciudad, por lo que sólo se estudian las variaciones de una forma de "ciudad" predeterminada, en vez de interrogarse sobre la esencia misma de "la ciudad como ser", es decir, emprender la construcción de una ontología de la ciudad. Este reto, posiblemente, provocaría el derrumbe de muchos de los discursos sobre la ciudad contemporánea, construyendo además una lectura alterna de la misma.

La tríada "laberíntico-fugaz-fortuito" no es una simple yuxtaposición de "ocurrencias" bonitas a partir de las cuales se podría repensar la ciudad. Permite una redefinición ontológica sobre lo que la ciudad es en su esencia; en otros términos, lo que hace que una ciudad sea una ciudad y no una simple aglomeración de personas con ciertas actividades sobre un territorio dado, bajo una determinada morfología espacial.

Una ciudad, por lo menos en el sentido que se ha atribuido tradicionalmente al concepto, ha de tener las 
tres características mencionadas. Pero además las tiene que poseer simultánea y articuladamente. No hay posibilidad de que un laberinto, sin el carácter fortuito y sin la fugacidad, constituya una ciudad. Tampoco es posible que los eventos de carácter fortuito o fugaz puedan constituirse en una representación de la ciudad, si no existe lo laberíntico que es su sustrato, no sólo físico sino también mental.

De hecho, las tres caracterizaciones hablan de lo mismo, pero se refieren a campos distintos. Lo laberíntico remite a lo espacial desde lo geográfico, o bien, a la organización del espacio mental —lo laberíntico de los sueños y de los imaginarios-. En tanto que lo fugaz refiere a lo temporal, y lo fortuito a lo social. Estamos hablando, entonces, de una complementariedad real, en tres campos articulados y difícilmente separables, de una "cierta" característica que es la marca de referencia que define la ciudad. En buena medida hablamos de la no linealidad del espacio, del tiempo y de las acciones sociales. La ausencia de un trazado fiable, permanente, seguro para nuestras acciones en el tiempo y en el espacio.

Esto es lo que distingue la ciudad del "campo" o, más bien, de las formas distintas de articulación entre la naturaleza y la sociedad que solían darse en el pasado. La comunidad, en sus diversas formas de inscripción espacial, desde el calpulli prehispánico, el pueblo tradicional europeo o las aldeas africanas, no ha ofrecido ni ofrecerá, para bien o para mal, la diversidad de espacios, de posibilidades ni de innovaciones que ha ofrecido, y lo sigue haciendo, la ciudad desde sus albores.

La cuestión que puede plantearse también, desde una perspectiva histórica, es si ciertas formas de asentamientos, como Tenochtitlan, entre otras, caben en esta formulación de la esencia de la ciudad que acabamos de proponer. No nos toca responder esta pregunta pero sí podemos afirmar que muchas formas actuales de asentamientos humanos, como las interminables periferias de las metrópolis mundiales, $\mathrm{y}$ particularmente las nuestras en México, distan de ser laberínticas, de ofrecer la fugacidad y el carácter fortuito que consideramos como esencia ontológica de la ciudad. Cabe reiterar que las características fundamentales de la ciudad no remiten a su morfología - traza, tipo de vivienda...- sino a los modos de vida. En este sentido, las investigaciones que hemos realizado en la periferia oriental de la ciudad de México apuntan a la linealidad de la vida cotidiana, y lo escasamente fortuito y fugaz de la misma.

El debate no debe enfocarse entonces en la morfología de la ciudad, si, por otra parte, planteamos que el modelo de urbanización actual dista de tener las condiciones como para que pueda ser calificado de urbano. La cuestión es, por ende, reconocer que quizás estamos entrando en una fase de "post-ciudad" en donde reina la urbanización sin ciudad. Esto lo insinuaron en forma profética autores como Françoise Choay (1970) o Murray Bookchin (1992).

Tampoco es aceptable que todo lo urbanizado no sea ciudad. La ciudad perdura, en su esencia ontológica tradicional, pero es evidente que ha sido reemplazada —¿quizás desde los sesenta? - por una urbanización que no es ciudad sino "otra cosa", de la cual es pertinente hacer la ontología y darle un nombre, bautizarla, lo que hasta ahora no se ha hecho, tal vez por el afán de seguir discutiendo sobre las formas de ciudad.

Significativamente, muchas ciudades que han perdurado como tales se han rodeado de estas urbanizaciones interminables. Inclusive, hemos encontrado un verdadero interés en muchos de sus habitantes por emprender un "regreso a la ciudad" (Bidou, Hiernaux y Rivière d'Arc, 2003) que, con frecuencia, sirve más para desvirtuar el espacio urbano todavía existente que para asegurar la permanencia de la ciudad.

Fenómenos como la "gentrificación" o la "turistificación" se han hecho presentes en muchas ciudades, desarrolladas o no. Pero estos procesos, fruto de una 
visión nostálgica, aunque no forzosamente negativa de la ciudad, no apoyan su permanencia, sino que trastornan las posibilidades de sostenerlas como tales. Así, los centros urbanos suelen volverse museos semivivos para la felicidad de los turistas, o el lugar de residencia de las nuevas burguesías que, antes que todo, reclaman que se eliminen todas las condiciones de lo fortuito y de lo fugaz, como pueden ser los "malvivientes, comerciantes ambulantes, prostitutas y demás vagos".

Se trata de una ciudad que quizás conserva el carácter laberíntico de su traza antigua, pero donde no se permite e inclusive se tiene un miedo exagerado a todo lo que no es controlado, fichado, conocido — véase el auge de la ciudad-filmada día y noche por cámaras de vigilancia- Este miedo es recurrente en muchas ciudades cuyos centros están pasando por el proceso de elitización o gentrificación, sea México, Londres — la más controlada del mundo-, Nueva York o París: "Nada malo puede pasar si nada fortuito se presenta", parecería ser el lema de nuestras ciudades "gentrificadas".

Quizás entonces es a Louis Wirth a quien debamos regresar para reencontrar esta "personalidad urbana" marcada por lo efímero, lo transitorio, la complejidad y la movilidad (Wirth, 1988), personalidad que distingue a la ciudad de las masas informes de nuestras urbanizaciones "difusas" (Chadouin, 2005).

Nuestras reflexiones anteriores no sólo remiten a la necesidad de una reflexión filosófica, de lo cual estas notas son apenas un esbozo. También podrían ser materia de una política urbana más inteligente y atenta a la realidad misma; que reflexione sobre la ciudad de mañana para construirla desde hoy.
Notas

${ }^{1}$ Donzelot, por ejemplo, habla de una "nueva cuestión urbana" que surge tanto de la expansión de la ciudad, como de las nuevas formas de organización del espacio urbano, particularmente, a partir de las nuevas segregaciones voluntarias (1999).

${ }^{2}$ Sobre los modelos de ciudades que responden a estas formas ortogonales, claramente Los Ángeles ha sido asumida como su paradigma. La difusión de este modelo y los resultados sobre la suburbanización, en Europa, Asia y América del Norte, acaban de ser tratados por numerosos autores en Berque, Bonnin y Ghorra-Gobin (2006), subrayando la dimensión imaginaria -entre otros en la relación con la naturaleza- de estas nuevas formas de asentamiento que se vuelven, como lo sugiere el título de la obra, el modelo de "la ciudad insostenible".

${ }^{3}$ En este sentido, la modernidad es, como bien lo subrayó Baudelaire, lo transitorio, lo fugitivo, lo contingente.

${ }^{4}$ En su obra clásica sobre la ciudad, Jean Remy (1960) planteaba hace ya cuarenta años que la variedad de la oferta era una dimensión esencial de lo urbano; aunque lo hiciera en términos esencialmente económicos, la reflexión sigue siendo pertinente para el mundo urbano actual.

${ }^{5}$ Cabe recordar que esta expresión fue introducida en la teoría sociológica por Robert Merton con referencia a "un dato imprevisto, anómalo y estratégico que se convierte en ocasión del desarrollo de teoría nueva o de la ampliación de una existente (...). Una investigación encaminada a comprobar una tesis arroja un subproducto fortuito que influye en teorías que no se habían tenido en cuenta al empezar la investigación" (Merton, 1995: 181).

${ }^{6}$ Este tema, ampliamente tratado también en la citada obra de Berque, Bonnin y Ghorra-Gobin (2006), se ha vuelto muy controvertido: numerosas regiones francesas se inquietan por la verdadera colonización de sus espacios -Provenza, Córcega...por residentes temporales ingleses o del resto del país, que compran propiedades que ocupan sólo parte del año. Claramente, la noción de identidad regional se asocia a la permanencia, la participación regulary comunitaria, que los residentes "golondrinas" no asumen sino parcialmente, aunque construyan un imaginario de una inserción en la comunidad como una meta esencial de su estancia. 


\section{Bibliografía}

Ascher, François, 1995, Metápolis ou l'avenir des villes, Odile Jacob, Paris.

Attali, Jacques, 1996, Chemin de sagesse (Traité du labyrinthe), Fayard, Paris.

—, 2003, L'bomme nomade, Fayard, Paris.

Bairoch, Paul, 1990, De Jérico a México (bistoria de la urbanización), Ed. Trillas, México.

Bauman, Zygmunt, 2003, La modernidad líquida, Fondo de Cultura Económica, México.

Bidou, Catherine, Daniel Hiernaux y Hélène Rivière d'Arc, 2003, Retours en ville, Descartes et Cie, Paris.

Bookchin, Murray, 1992, Urbanization without cities (The rise and decline of citizenship), Black Rose Books, Montréal.

Chadouin, Olivier, 2005, La ville des individus (sociologie, urbanisme et architecture, propos croisés), L'Harmattan, colección Villes et Entreprises, Paris.

Choay, Françoise, 1970, El urbanismo, utopias y realidades, Lumen, Barcelona.

Dematteis, Giuseppe, 1998, “Suburbanización y periurbanización: Ciudades anglosajonas y ciudades latinas", en Monclús, F. J. (ed.), La ciudad dispersa, Centre de Cultura Contemporania de Barcelona, Barcelona, pp. 17-33.

Donzelot, Jacques, 1999, "La nouvelle question urbaine", en Esprit, N. "11, "Quand la ville se défait", pp. 87-114.

Frisby, David, 1992, Fragmentos de la modernidad (Teorías de la modernidad en la obra de Simmel, Kracauer y Benjamin), Visor, Madrid.

García Canclini, Néstor, 2004, Diferentes, desiguales y desconectados: mapas de la interculturalidad, Gedisa, Barcelona.

Garreau, Joel, 1991, Edge City: Life on the New Frontier, Doubleday, New York.

Gottman, Jean y Robert A. Harper, 1990 (comps.), Since Megalopolis (The urban Writings of Jean Gottman), John Hopkins, Baltimore.

Harvey, David, 2003, Paris, capital of modernity, Routledge, Nueva York y Londres.

Hiernaux, Daniel, 2005, "Identidades móviles o movilidad sin identidad. El individuo moderno en transformación", en Revista de Geografía Norte Grande, N. ${ }^{\circ}$ 34, Pontificia Universidad Católica de Chile, Santiago de Chile, pp. 5-17.

—, 2006, en prensa, "Geografía de los espacios y los tiempos efímeros y fugaces”, en Nogué, Joan y Joan Romero, Las nuevas geografías, Ed. Tirant Lo Blanch, Valencia Jackson,
John Brinckerhoff, 1994, A Sense of Place, a Sense of Time, Yale University Press, New Haven y Londres.

Kropotkine, Piotr, 2003, El estado, en http:/ /www.antorcha.net/ biblioteca_virtual/politica/estado/estado.html

Lévy, Jacques, 2003, "Urbanisation honteuse, urbanisation heureuse", en Roncayolo, Marcel, Thierry Paquot, Jacques Lévy, Olivier Mongin, Philippe Cardinali, De la ville et du citadin, Parenthèses, Paris.

Merton, Robert, 1995, Teoría y estructuras sociales, FCE, primera edición en inglés 1949, México.

Paden, Roger, 2001, "The two professions of Hippodamus of Miletus", Philosophy and Geography, vol. 4, Núm. 1, pp. 25-48.

Perec, George, 1999 [1974], Especies de espacios, Montesinos, Barcelona.

Pirenne, Henri, 1975, Historia social y económica de la edad media, Fondo de Cultura Económica, México.

Remy, Jean, 1966, La ville, phénomène économique, Editions Vie Ouvrière, Bruxelles.

Roth, Joseph, 2000, Las ciudades blancas, Ed. Minúscula, Barcelona.

Roux, Michel, 1999, Géographie et complexité (les espaces de la nostalgie), L'Harmattan, colección Ouverture philosophique, Paris.

Sassen, Saskia, 1991, The global City: New York, London, Tokyo, Princeton University Press, Princeton.

Silva, Armando, 1992, Imaginarios urbanos (cultura y comunicación urbana), Tercer Mundo Editores, Bogotá.

Simmel, Georg, 1986, "Las grandes urbes y la vida del espíritu”, en Simmel, Georg, El individuo y la libertad. Ensayos de crítica de la cultura, colección historia/ciencia/sociedad, N. ${ }^{\circ}$ 198, Península, Barcelona, pp. 247-263.

Smith, Neil, 1996, The new Urban Frontier: Gentrification and the Revanchist City, Routledge, Londres.

Soja, Edward, 2000, Postmodern metropolis: Critical Studies of Cities and Regions, Blackwell Publishers, Oxford, UK.

Tonnies, Ferdinand, 1979 [1935], Comunidad y asociación (el comunismo y el socialismo como formas de vida social), Península, Barcelona.

Unikel, Luis, 1976, El desarrollo urbano de México, El Colegio de México, México.

Weber, Max, 1964, Economía y Sociedad, Fondo de Cultura Económica, México.

Wirth, Louis, 1988 [1938], "El urbanismo como modo de vida", en Bassols, Mario et al. (comps.), Antología de sociología urbana, Universidad Nacional Autónoma de México, México, pp. 162-182. 